\title{
ANÁlise de EXTRATOS DE PLANTAS POR CCD: UMA METODOLOGia APLICADA À DisCiPLiNa "QUÍMICA ORGÂNICA"
}

\author{
Mariana H. Chaves \\ Universidade Federal do Piauí - Departamento de Química - Ininga - 64049 - 550 - Teresina - PI
}

Recebido em 31/10/96; aceito em 20/1/97

\begin{abstract}
ANALYSIS OF EXTRACTS OF PLANTS BY TLC: A METHODOLOGY APPLIED IN THE "ORGANIC CHEMISTRY" DISCIPLINE. Extracts of the regional plants Annona squamosa and Annona muricata were analysed by silica gel thin-layer chromatography using adequate systems of solvents and spray reagents. Carbohydrates, amino acids, alkaloids, flavonoids and terpenoids were detected in both species. These data agree with those on the literature about phytochemistry of the Annonaceae.
\end{abstract}

Keywords: Annona squamosa; Annona muricata; TLC; teaching of chemistry.

\section{INTRODUÇÃO}

O tópico "análise de misturas" é abordado normalmente, a partir de uma mistura hipotética ou na prática a partir de uma mistura artificial preparada com substâncias puras. O método geral comumente empregado na análise consiste em separar os componentes e identificá-los posteriormente utilizando reações de classe $^{1}$. Vale ressaltar que torna-se impossível apresentar em um livro texto uma gama de processos que sejam aplicáveis sem modificação à grande variedade de combinações de misturas que podem ser fornecidas. A falta de mais livros textos e a dificuldade de aquisição dos existentes pelos alunos levou ao desenvolvimento de uma metodologia para o estudo de análise de misturas na disciplina Química Orgânica III. O programa desta disciplina no currículo de Bacharelado e Licenciatura em Química da Universidade Federal do Piauí inclui o estudo dos tópicos: análise de misturas, critérios de pureza e o uso da espectrometria no UV, IV, RMN e massas na identificação de estruturas de substâncias orgânicas. Neste curso o tópico "análise de misturas" foi abordado utilizando-se como exemplo extratos de plantas regionais.

Inicialmente, duas espécies vegetais de distribuição ampla no Estado do Piauí foram escolhidas para estudo: Annona squamosa (ata) e Annona muricata (graviola), ambas pertencentes à família Annonaceae e com estudos fitoquímicos já relatados na literatura ${ }^{2-7}$. Escolheu-se para análise espécies desta família em função de serem ricas em metabólitos pertencentes aos vários grupos fitoquímicos, pois o ojetivo, além da aplicação da extração líquido-líquido, foi a obtenção de um perfil cromatográfico em camada delgada de sílica dos diversos extratos visando a investigação de carboidratos, ácidos aminados, alcalóides, flavonóides e terpenóides.

\section{EXPERIMENTAL}

Procedimentos Experimentais Gerais: As placas cromatográficas foram preparadas utilizando camadas de $0,25 \mathrm{~mm}$ de uma mistura (25 g) de 3:1 de sílica gel 60 (artigo 7731) e sílica $\mathrm{PF}_{254+366}$ (artigo 7748), ambas da Merck, suspensa em aproximadamente $50 \mathrm{~mL}$ de água. A solução de sulfato cérico foi preparada a partir de $2,1 \mathrm{~g}$ de $\mathrm{Ce}\left(\mathrm{SO}_{4}\right)_{2} .5 \mathrm{H}_{2} \mathrm{O}$ dissolvido em $15 \mathrm{~mL}$ de $\mathrm{H}_{2} \mathrm{SO}_{4}$ concentrado e adicionado a $800 \mathrm{~mL}$ de água. $\mathrm{O}$ reagente Dragendorf foi preparado a partir de $0,85 \mathrm{~g}$ de nitrato de bismuto $\mathrm{Bi}\left(\mathrm{NO}_{3}\right)_{3} \cdot 4 \mathrm{H}_{2} \mathrm{O}$ dissolvido em $40 \mathrm{~mL}$ de $\mathrm{H}_{2} \mathrm{O}$ e $10 \mathrm{~mL}$ de ácido acético glacial, seguido por adição de $8 \mathrm{~g}$ de iodeto de potássio dissolvido em $20 \mathrm{~mL}$ de água. A solução de ninidrina foi preparada a partir $30 \mathrm{mg}$ de ninidrina $\left(\mathrm{C}_{9} \mathrm{H}_{6} \mathrm{O}_{4}\right)$, dissolvida em $10 \mathrm{~mL}$ de $\mathrm{n}$-butanol, seguido por adição de $0,3 \mathrm{~mL}$ de ácido acético glacial. A solução de anisaldeído foi preparada pela adição de $0,5 \mathrm{~mL}$ de anisaldeído $\left(\mathrm{C}_{8} \mathrm{H}_{8} \mathrm{O}_{2}\right)$ em $9 \mathrm{~mL}$ de etanol $(95 \%), 0,5 \mathrm{~mL}$ de $\mathrm{H}_{2} \mathrm{SO}_{4}$ concentrado e $0,1 \mathrm{~mL}$ de ácido acético glacial. As placas borrifadas com solução de sulfato cérico, ninidrina ou anisaldeído foram aquecidas por 5-10 minutos.

Material Vegetal: Folhas de ata (Annona squamosa) foram coletadas no bairro Monte Castelo-Teresina-PI e folhas de graviola (Annona muricata) no sítio Recreio, $\mathrm{Br} 316, \mathrm{Km} \mathrm{22}$, Teresina-PI. As exsicatas destes espécimens encontram-se depositadas no Herbário Graziela Barroso com os números 9482 e 9435 respectivamente e foram identificadas pelos professores: Airan Silva Lopes e Francisco Maurício Teles Freire.

Descrição da Metodologia: Para execução da metodologia proposta, a turma foi dividida em quatro equipes constituídas cada uma por no máximo três alunos. Duas equipes, uma com folhas de graviola e a outra com folhas de ata seguiram o esquema 1 e as outras duas o esquema 2.

As equipes que trabalharam seguindo o esquema 1 tiveram como objetivo obter para as duas espécies, um perfil cromatográfico do extrato etanólico e das frações decorrentes deste após extração líquido-líquido, enquanto que o objetivo das equipes que procederam segundo o esquema 2 foi a aplicação da extração com solventes quimicamente ativos na obtenção de alcalóides ${ }^{8}$, bem como a obtenção do perfil cromatográfico das fases alcaloídicas e orgânicas neutras decorrentes desta extração ${ }^{9,10}$.

Os extratos obtidos mediante esquema 1 foram concentrados, pesados e analisados por cromatografia em camada delgada comparativa de sílica utilizando os seguintes sistemas de solventes: hexano/acetato de etila $(8: 2)$, clorofórmio/metanol/ hidróxido de amônio (95:5:0,5) e clorofórmio/metanol/água (65:30:5). As placas foram reveladas com solução de sulfato cérico para investigação de substância de natureza terpenoídica e flavonoídica e com reagente Dragendorf para investigação de alcalóides ${ }^{9,10}$. As fases butanólica e aquosa foram ainda submetidas a cromatografia comparativa em placa de sílica eluída com clorofórmio/metanol/água (5:4:1) e revelada com ninidrina para investigação de ácidos aminados e, com n-butanol/ácido acético/éter etílico/água (9:6:3:1) revelada com anisaldeído, para investigação de carboidratos ${ }^{9,10,11}$.

Os extratos obtidos mediante esquema 2 foram concentrados, pesados e analisados por cromatografia em camada delgada comparativa de sílica. As placas realizadas com o extrato bruto e fases alcaloídicas foram eluídas com clorofórmio/ 


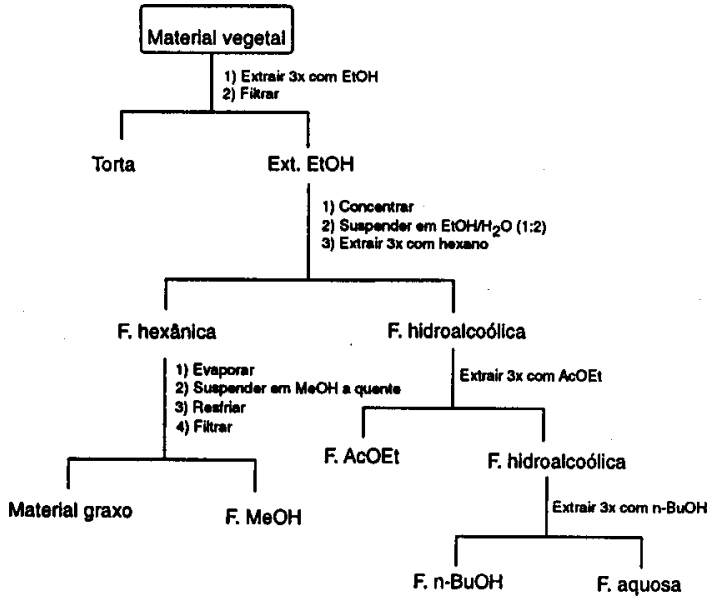

Esquema 1. Fluxograma da extração líquido - líquido.

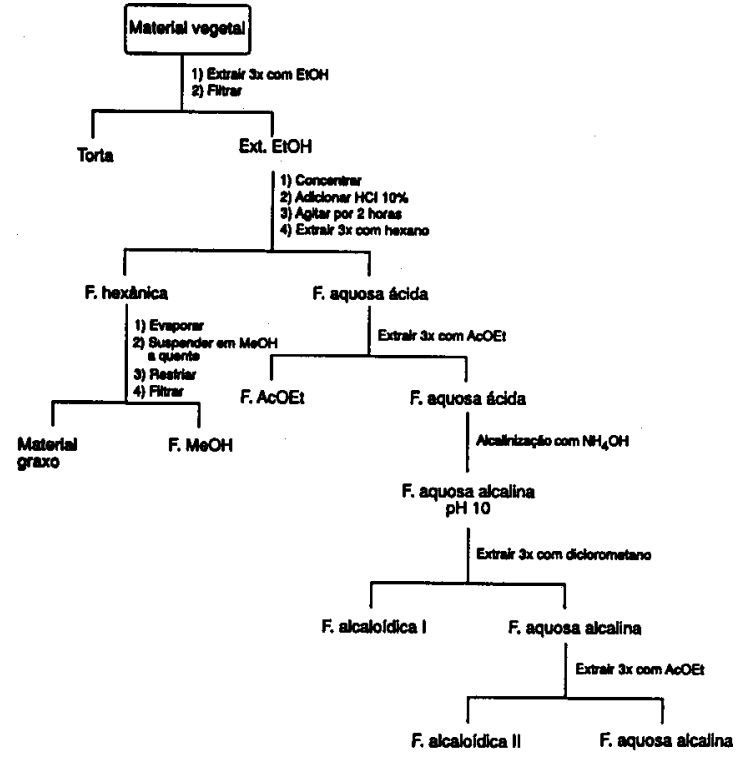

Esquema 2. Fluxograma da extração dos alcalóides.

metanol/hidróxido de amônio (95:5:0,5) e como reveladores foi usado irradiação UV (254 e $356 \mathrm{~nm}$ ) e reagente Dragendorf para investigação de alcalóides ${ }^{9,10}$. O extrato bruto e as fases orgânicas neutras (material graxo, metanólica e acetato de etila) foram ainda submetidas a cromatografia comparativa em placas de sílica eluídas com hexano/acetato de etila (8:2), e clorofórmio/metanol/água (65:30:5) reveladas com solução de sulfato cérico para investigação de substâncias de natureza terpenoídicas e flavonoídicas respectivamente.

\section{RESULTADOS}

Os resultados obtidos pelos alunos foram apresentados através de relatórios e expostos na forma de painéis a fim de possibilitar maior discussão entre os grupos. As equipes que trabalharam seguindo o esquema 1 observaram que o extrato bruto, fase metanólica e, em intensidade menor, o material graxo apresentaram manchas rósea e azul em placa eluída com hexano/acetato de etila $(8: 2)$ e revelada com solução de sulfato cérico. Isto sugeriu a presença de substâncias de natureza terpenoídica. Ao compararem os resultados da placa com estes extratos versus o padrão da mistura dos esteróides distribuídos amplamente na natureza (estigmasterol e sitosterol) utilizando o mesmo sistema de solventes constataram que estas substâncias estão presentes na ata porém não na graviola. Observaram, também, que as fases acetato de etila, butanólica e aquosa apresentaram manchas amarelas e cinzas em placa eluída com clorofórmio/MeOH/água (65:30:5) e revelada com solução de sulfato cérico. A cor cinza sugeriu a presença de açúcares e a amarela de flavonóides. A presença de açúcares foi confirmada por eluição de placa destes extratos em n-butanol/ácido acético/ éter etílico/água (9:6:3:1) e revelação com solução de anisaldeído. Entre as cores observadas, a azul $\left(\mathrm{R}_{\mathrm{f}} \sim 0,47\right)$ e verde $\left(R_{\mathrm{f}} \sim 0,55\right)$ sugeriram a presença de ribose e ranminose respectivamente $^{10}$. Observaram ainda que a fase aquosa e em extensão menor, a fase butanólica apresentaram manchas púrpura e amarela em placa eluída com clorofórmio/MeOH/água (5:4:1) e reveladas com solução de ninidrina. $\mathrm{O}$ aparecimento destas cores é indicativo da presença de ácidos aminados, sendo que a cor amarela deve ser relativa à prolina conforme padrão utilizado. Finalmente observaram que as fases acetato de etila e butanólica apresentaram manchas alaranjadas em placa eluída com clorofórmio/MeOH/ $/ \mathrm{NH}_{4} \mathrm{OH}(95: 5: 0,5)$ e revelada com reagente Dragendorf, sugerindo a presença de alcalóides.

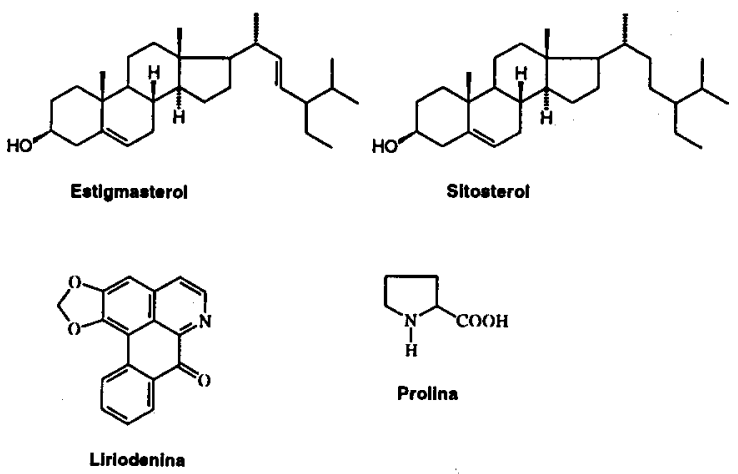

As equipes que trabalharam seguindo o esquema 2 observaram que as fase alcaloídicas apresentaram manchas alaranjadas em placas eluídas com clorofórmio/ $\mathrm{MeOH} / \mathrm{NH}_{4} \mathrm{OH}$ (95:5:0,5) e reveladas com reagente Dragendorf confirmando a presença de alcalóides. Ao utilizarem o padrão da liriodenina, um alcalóide oxoaporfínico distribuído amplamente em plantas da família Annonaceae e facilmente identificado pela coloração e fluorescência amarela intensa apresentada em placas reveladas no visível e ultravioleta respectivamente, foi possivel evidenciálo apenas na ata. Observaram também, que a fase orgânica neutra (acetato de etila) apresentou manchas amarela e cinza quando eluída com clorofórmio/MeOH/água (65:30:5) e reveladas com solução de sulfato cérico, sugerindo a presença de flavonóides e carboidratos respectivamente. Evidenciaram também a presença de substâncias de natureza terpenoídicas quando as placas realizadas com as fases orgânicas neutras (material graxo e fase metanólica) foram eluídas com hexano/acetato de etila (8:2) e reveladas com solução de sulfato cérico. Confirmaram inclusive os resultados observados pelas equipes que trabalharam seguindo o esquema 1 no que se referiu à presença da mistura de estigmasterol e sitosterol somente na ata. Estes resultados estão consistentes com os dados relatados na literatura relativos à fitoquímica de Annonaceae ${ }^{12}$.

\section{CONCLUSÃO}

A metodologia desenvolvida mostrou-se bastante eficiente, uma vez que possibilitou ao aluno adquirir familiaridade com as técnicas de extração líquido-líquido com solventes reativos e não reativos e com a cromatografia em camada delgada. Além disso, forneceu informações sobre a polaridade das substâncias existentes nos diversos extratos, bem como sobre a constituição 
química da planta. Finalmente, a metodologia desenvolvida, além de incentivar os alunos para iniciação científica, forneceu uma boa base para aqueles que pretendem trabalhar na área de produtos naturais.

\section{AGRADECIMENTOS}

Gostaríamos de agradecer aos alunos que viabilizaram este trabalho: Antônio João Portela, Doris Almendra, Ferdinand Bezerra, Francílio Oliveira, Gabriel Rodrigues, Luzemir Santos, Maura Franco, Moisés Batista, Rosemberg Rocha, Sidney de Lima e Silvio Lima.

\section{REFERÊNCIAS}

1. Vogel A. I.; Quimica Orgânica: análise orgânica qualitativa 1988, p 1149.

2. Rieser, M. J.; Kozlowski, F. J.; Wood, K. W. e McLaughlin, J. L.; Tetrahedron Lett. 1991, 32, 1137.

3. La, H.; Hui, Y. H.; Rupprecht, J. K.; Liu, Y. M.; Wood, K. V.; Smith, D. L.; Chang, C. J. e McLaughlin, J. L.; J. Nat. Prod. 1990, 53, 81.
4. Born L.; Lieb, F.; Lorentzen, J. P.; Moeschier, H.; Nofon, M.; Söllner, R. e Wendisch, D.; Planta Med. 1990, 56, 312 .

5. Lieb, F.; Nonfon, M.; Wachendorff-Neumann, U. e Wendisch, D.; Planta Med. 1990, 56, 317.

6. Myint, S. H.; Cortes, D.; Laurens, A.; Hocquemiller, R.; Leboeuf, M.; Cavé, A.; Cotte, J. e Quéro, A.-M.; Phytochemistry 1991, 30, 3335.

7. Arriaga, A. M. C.; Machado, M. I. L.; Craveiro, A. A.; Silveira, E. R.; Braz Filho, R. e Dourado, R. C. M.; $19^{a}$ Reunião Anual da SBQ, Poços de Caldas-MG 1996.

8. Chaves, M. H.; Tese de Doutoramento, Instituto de Química da Universidade de São Paulo, 1996.

9. Krirchner, J. G.; Techniques in Organic Chemistry, Interscience, New York 1967, v.12, p. 147.

10. Stahl, E.; Thin Layer Chromatography. Verlag, Berlim 1969, p. 299.

11. Ikan, R.; Natural Products. 2. ed. Academic Press, San Diego 1991 p. 90.

12. Leboeuf, M.; Cavé, A.; Bhaumik, P. K.; Mukherjee, B. e Mukherjee, R.; Phytochemistry 1982, 21, 2783. 